\section{Comment on "Post-Wildfire Logging Hinders Regeneration and Increases Fire Risk"}

\author{
M. Newton, ${ }^{1}$ S. Fitzgerald, ${ }^{2}$ R. R. Rose, ${ }^{1}$ P. W. Adams, $^{3}$ S. D. Tesch, ${ }^{3}$ \\ J. Sessions, ${ }^{3 *}$ T. Atzet, ${ }^{4}$ R. F. Powers, ${ }^{5}$ C. Skinner ${ }^{5}$
}

Donato et al. (Brevia, 20 January 2006, p. 352) concluded that logging after wildfire kills natural regeneration and increases fire risk. We argue that their paper lacks adequate context and supporting information to be clearly interpreted by scientists, resource managers, policy-makers, and the public.

$\mathrm{D}$ onato et al. (1) recently concluded that logging 2 to 3 years after wildfire kills natural regeneration and increases fire risk. The research may make a valuable contribution, but the study lacks adequate context and supporting information to be clearly interpreted. Here, we discuss the paper's methods and conclusions in the context of relevant management objectives and the forestry knowledge base concerning natural regeneration processes, mortality from logging, and fuel accumulations in southwestern Oregon and northwestern California.

Donato et al. (1) made inferences about natural regeneration processes, mortality from logging, and fuel accumulations without presenting key information regarding (i) agency postfire management directives for reforestation or downed wood levels (2), (ii) implications of delays in postfire plan implementation, or (iii) important environmental and disturbance descriptors such as plant associations, fire intensity, seed tree proximity, and weather patterns. Results from their study cannot be readily extrapolated because it was a short-term observational study of site-specific forest operations governed by agency management objectives. Other management plans, operations, or conditions could yield different results (3). In the case of the 2002 Biscuit Fire, logging was postponed for 2 years, allowing more seeds to germinate and increasing seedling exposure to injury during logging (4).

Donato et al. cite a lack of scientific data regarding the management of public forests after large fires. However, it should be noted that conifer reforestation (planted and natural) and vegetation ecology have been widely studied in the region. Studies show variable responses

${ }^{1}$ Department of Forest Science, ${ }^{2}$ Department of Forest Resources, ${ }^{3}$ Department of Forest Engineering, Oregon State University, Corvallis, OR 97331, USA. ${ }^{4}$ Atzet Ecological Consulting, Grants Pass, OR 97528, USA. ${ }^{5}$ Pacific Southwest Research Station, Redding, CA 96002, USA.

*To whom correspondence should be addressed. E-mail: john.sessions@oregonstate.edu with plant association, competing vegetation, local climate, soils, and other factors $(5,6)$. Hobbs et al. (5) provide a synthesis of 13 years of research in southern Oregon and northern California. Fewer studies have examined reforestation after wildfire, especially over longer periods $(4,7-9)$, but damage to natural regeneration after delayed salvage logging was reported more than 50 years ago $(4,8)$.

Donato et al. (1) reported that natural conifer regeneration on sites affected by the Biscuit Fire was common, without also describing proximity to recent seed crops, weather, and competing vegetation, and further suggested that planting may be unnecessary to achieve some reforestation goals. Caution is urged when projecting forest development from such early conifer survival results. Competing vegetation can develop rapidly after disturbance in this region and can dramatically affect small conifer seedling survival and growth (5-7). Agency reforestation objectives were to establish a minimum number of suitable conifer trees in "free to grow" condition (2). Given the documented competitiveness of shrubs and hardwoods, as well as the historical variability in natural regeneration success, federal managers specified tree planting after salvage to better ensure the desired density and distribution of conifers (2). Artificial reforestation practices are science-based and well tested in southwestern Oregon and northwestern California $(3,5,7)$. Performance of planted seedlings also commonly exceeds that of natural seedlings, which will assist in achieving some objectives $(5,7,10)$.

It is also inappropriate to compare the 1- to 2year-old seedling density measured in (1) with "free to grow" stocking standards prescribed under state regulations (11) and federal firerecovery goals (2). Such standards are always defined at an older age or larger size after early seedling mortality stabilizes. Related protocols for conducting stocking surveys are designed to estimate both seedling density and distribution (12). The belt transects used by Donato et al. (1) also differ from systematic plot grids widely used in forestry stocking surveys to determine the "number of well-distributed trees per unit area." Therefore, their reported results cannot be directly compared with regional stocking standards $(2,11,12)$, because there is no indication of spatial distribution.

We also note that the term "logging" used in (1) is not adequately descriptive (13). Logging prescriptions provide a flexible silvicultural tool with capabilities and impacts that vary by equipment, management objectives, and site-specific conditions $(4,5)$. Seedling protection was not prescribed in the postfire harvests studied in (1) because prompt salvage and subsequent planting were planned (2). Logging plans can be designed to limit damage to seedlings when desirable $(4,5)$. Notably, the seedling damage reported by Donato et al. cannot be extrapolated without improved descriptions of the logging or followup slash treatments $(5,7,13)$.

Turning to the data presented on fuel loads after the Biscuit Fire, Donato et al. reported increased "fire risk" as a consequence of increased downed woody fuels. However, what they actually assessed was fuel quantity in two fuel size classes. Moreover, they did not describe fuel continuity, a major factor contributing to fire behavior, nor did they present approximate differences in projected fire behavior, which can be determined using standard fire models $(14,15)$. Conclusions suggesting that future fire hazard is less from deteriorating standing trees than from observed postlogging slash are unsupported speculation as presented. Management directives specifically included leaving logging slash for soil protection and wildlife habitat in areas deficient in downed wood as a function of plant association, topographic aspect, and fire intensity (2). On some sites, the observed increases in slash after logging may have been an intended result of the prescriptions, but Donato et al. provide insufficient information to discern this.

We believe the Donato et al. paper (1) could have better informed the discussion of this complex topic for all audiences with a more accurate title, use of standard forestry protocols, more complete disclosures of methods and management objectives, and less speculation beyond the presented data. If the authors were constrained by print space limitations, we urge them to use alternative mechanisms to disclose details critical to understanding and interpreting their results.

\section{References}

1. D. C. Donato et al., Science 311, 352 (2006).

2. USDA Forest Service. Biscuit Fire Final Environmental Impact Statement, Appendix D (reforestation), Appendix G (dead wood management) (USDA Forest Service, Grants Pass, OR, 2004) www.fs.fed.us/r6/rogue-siskiyou/biscuit-fire/feis.

3. J. Sessions, P. Bettinger, R. Buckman, M. Newton, J. Hamann, J. Forestry 102, 38 (2004).

4. D. F. Roy, Salvage Logging May Destroy Douglas-Fir Reproduction: USFS California Forest and Range Exp. Stn. Research Note 107 (U.S. Forest Service, Berkeley, CA, 1956). 
5. S. D. Hobbs et al., Eds. Reforestation Practices in Southwestern Oregon and Northern California (Oregon State University Forest Research Laboratory, Corvallis, OR, 1992).

6. J. K. Agee, Fire Ecology of Pacific Northwest Forests (Island Press, Washington, DC, 1993).

7. ]. C. Stuart, M. C. Grifantini, L. Fox III, For. Sci. 39, 561 (1993).

8. L. Isaac, J. Forestry 21, 492 (1930).

9. R. Everett et al., Int. J. Wildland Fire 9, 223 (1999).
10. W. D. Shepperd, C. B. Edminster, S. A. Mata, West. J. Appl. For. 21, 19 (2006).

11. Oregon Department of Forestry, Oregon Forest Practices Administrative Rules and Abridged Forest Practices Act, March 2004.

12. U.S. Department of the Interior Bureau of Land Management, Oregon State Office, Regeneration Stocking Surveys Handbook, H-5705-1, 2003, Release 5-249 (USDI BLM, Portland, OR, 2003).

13. J. D. Mclver, L. Starr, West. J. Appl. For. 16, 159 (2001).
14. K. Brown, E. D. Reinhardt, K. A. Kramer, 2003, Coarse Woody Debris: Managing Benefits and Fire Hazard in the Recovering Forest (USDA Forest Service, Rocky Mt. For. Res. Sta. RMRS-GTR-105, Missoula, MT, 2003).

15. R. C. Rothermel, How to Predict the Spread and Intensity of Forest and Range Fires (USDA Forest Service, Intermountain Research Station, Ogden, UT, 1983).

21 February 2006; accepted 6 July 2006

10.1126/science. 1126478 